\title{
HIGHLIGHT
}

\section{Mc3 and Mc4 receptors: complementary role in weight control}

\author{
M L Raffin-Sanson ${ }^{1,2}$ and J Bertherat ${ }^{2}$ \\ ${ }^{1}$ Service de Medecine Interne 3, Hôpital Ambroise Paré, 9 ave Ch de Gaulle 92240, Boulogne/Seine, France \\ ${ }^{2}$ CNRS UPR 1524, CHU Cochin, 27 rue du Fg-St-Jacques, 75014, Paris, France \\ (Correspondence should be addressed to J Bertherat; E-mail: jerome.bertherat@cch.ap-hop-paris.fr)
}

Energy stores are maintained relatively constant in mammals, in spite of large variation in food availability and physical activity. This tight regulation is achieved by an endocrine feedback loop initiated by leptin. Leptin, produced by the adipocytes, signals nutritional status to the hypothalamus. Its concentration in plasma is correlated with adipose tissue mass and acutely decreases with fasting. Leptin signal triggers a neuroendocrine response involving neuropeptides that modulate appetite and energy expenditure. Some of them also influence pituitary secretions, thus mediating the adaptive hormonal responses associated with food deprivation: changes in circulating thyroid hormones levels, suppression of reproductive capacity and linear growth. Orexigenic peptides (neuropeptide Y, orexins, etc) are suppressed by leptin whereas anorexigenic signals are stimulated. Among them, the central melanocortin system plays a pivotal role in regulation of energy homeostasis (Fig. 1).

Proopiomelanocortin (POMC) expression in the hypothalamic arcuate nucleus is induced by leptin. The precursor is processed by the prohormone convertases $\mathrm{PC} 1$ and $\mathrm{PC} 2$ into alpha melanocyte stimulating hormone $(\alpha \mathrm{MSH})$, the principle agonist of the two melanocortin receptor isoforms Mc3 and Mc4. Another level of complexity is added by agouti-related protein (AgRP), a physiological antagonist of Mc3 and Mc4 receptors (Mc3r and Mc4r), also expressed in the arcuate nucleus and inhibited by leptin $(1,2)$. Genetic or pharmacological disruption of this loop causes obesity in both humans and rodents. POMC deficient mice and humans are hyperphagic and obese. Infusion of a synthetic antagonist or overexpression of the melanocortin antagonist AgRP produces a similar phenotype. Conversely, intraventricular infusion of $\alpha \mathrm{MSH}$ or synthetic agonists causes anorexia and weight loss.

Which one, from the two melanocortin receptor isoforms, mediates the effect of the melanocortin system on energy stores? Both receptors are present at high levels in the hypothalamus. Mc $3 \mathrm{r}$ is much more widely expressed, being also detected in brain, adipose tissue and skeletal muscle. Many studies have established the importance of Mc4r in the control of energy homeostasis: Mc4r deficient mice are severely obese and hyperphagic (3). The effect on metabolic rate is unclear. Mc4r selective agonists cause anorexia and weight loss. These studies demonstrate the pivotal role of Mc4r in feeding behaviour. However, the physiological function of $\mathrm{Mc} 3 \mathrm{r}$ has remained largely unknown.

Two recent reports analysing Mc3r knock out (KO) mice $(4,5)$ have addressed this question. Mutant mice were born at the expected frequency indicating that the KO was not associated with embryonic or neonatal lethality. All mice were viable and fertile through adulthood. Homozygous null Mc3r mice were not (or were only slightly) overweight, but fat mass of $\mathrm{Mc}^{3} \mathrm{r}^{-/-}$ mice was approximately double that of wild type or heterozygous mice, whereas lean body mass was reduced. $\mathrm{Mc} \mathrm{r}^{-1-}$ mice did not escape obesity when

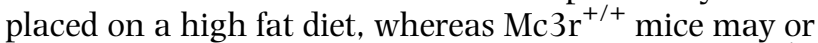
may not gain weight in the same situation. $\mathrm{Mc}^{-1-}$ mice did not exhibit increased food intake, even being hypophagic in some groups (males on regular chow diet). Metabolic rate was normal in these animals. Thus, increased feed efficiency, not hyperphagia, contributed to increased fat mass in ${\mathrm{Mc} 3 \mathrm{r}^{-1-}}^{-}$mice (feed efficiency is defined as the ratio of weight gain to food intake). Decreased locomotor activity reached statistical significance in females (4) and in males (5). Thus, reduced energy expenditure could also contribute to the phenotype.

$\mathrm{Mc} 3 \mathrm{r}^{-/-}$mice were hyperleptinemic and developed mild hyperinsulinaemia but had normal corticosterone and total thyroxine $\left(\mathrm{T}_{4}\right)$ levels. Their body length was significantly shorter than that of the wild-type littermates, whereas $\mathrm{Mc} 4 \mathrm{r}^{-1-}$ mice were longer than the controls.

These studies demonstrate that, in contrast to Mc4r which mainly controls food intake, Mc3r regulates fat stores by a peculiar metabolic pathway (Fig. 1).

Consistent with the non-redundant role of the two receptors on energy homeostasis, mice lacking both $\mathrm{Mc} 3$ and Mc4 receptors become heavier than $\mathrm{Mc} 4 \mathrm{r}^{-/-}$ mice. Most probably, double mutants are hyperphagic due to absent Mc4rs, and store ingested calories more efficiently because of the lack of Mc3r signalling.

In man, heterozygous mutation in the Mc4r has been reported in obese children, with a relatively high prevalence $(4 \%)$. Initial studies in search of a linkage between the locus encoding Mc3r and high body mass index brought conflicting results. In fact, Mc3r mutations are not expected to be an independent risk factor 


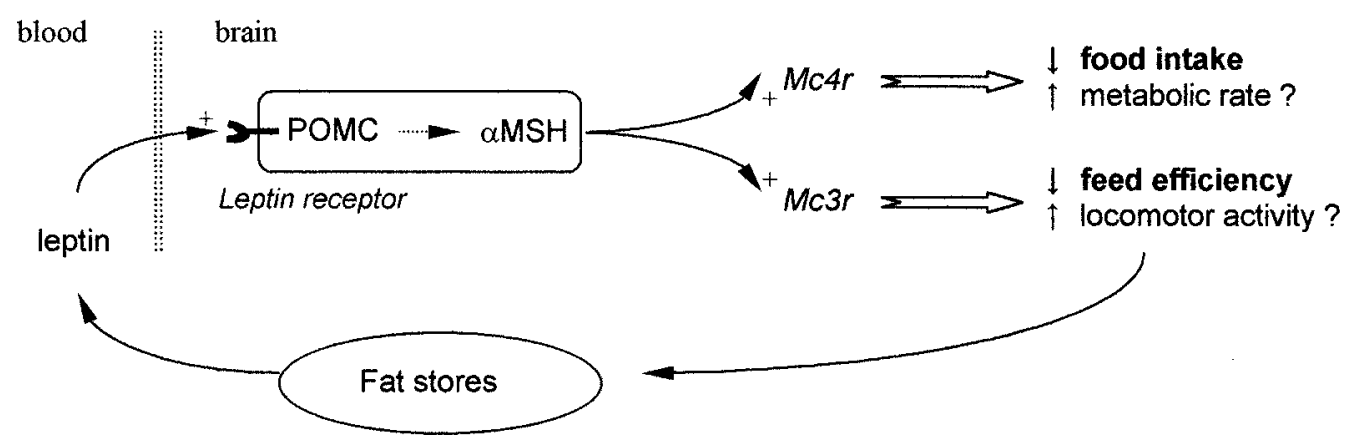

Figure 1 Leptin signalling through melanocortin neurons. POMC neurons are activated by leptin. AlphaMSH is produced and binds two different melanocortin receptor isoforms, Mc4 and Mc3. Stimulation of post-synaptic neurons expressing Mc4r has a dramatic effect in reducing food intake and may also increase metabolic rate. Activation of the Mc3r pathway decreases storage efficiency of ingested calories and may increase energy expenditure through locomotory behaviour.

for obesity. Isolated disruption of Mc3r signalling in rodents results in increased fat mass, but not high body mass index, except when the animals are exposed to a high fat diet or when other alleles promoting fat storage are also present. Further investigation is required to determine the extent to which mutations in Mc3r may contribute to human obesity.

\section{References}

1 Cowley MA, Pronchuk N, Fan W, Dinulescu DM, Colmers WF \& Cone RD. Integration of NPY, AGRP, and melanocortin signals in hypothalamic paraventricular nucleus: evidence of a cellular basis for the adipostat. Neuron 199924 155-163.

2 Fan W, Boston BA, Kesterson RA, Hruby VJ \& Cone RD. Role of melanocortinergic neurons in feeding and the agouti obesity syndrome. Nature $1997 \mathbf{3 8 5}$ 165-168.
3 Huszar D, Lynch CA, Fairchild-Huntress V, Dunmore JH, Fang Q, Berkemeier LR et al. Targeted disruption of the melanocortin 4 receptor results in obesity in mice. Cell 199788 131-141.

4 Chen AS, Marsh DJ, Trumbauer ME, Frazier EG, Guan XM, Yu H et al. Inactivation of the mouse melanocortin 3 receptor results in increased fat mass and reduced lean body mass. Nature Genetics 200026 97-102.

5 Butler AA, Kesterson RA, Khong K, Cullen MJ, Pelleymounter MA, Dekoning J et al. A unique metabolic syndrome causes obesity in the melanocortin 3 receptor deficient mouse. Endocrinology 2000141 3518-3521.

Received 23 November 2000 Accepted 24 November 2000 